\title{
Insights into the mechanisms of cadmium accumulation by Theobroma Cacao using stable isotope analysis
}

\author{
DR. REBEKAH ET MOORE ${ }^{1}$, LAUDINE MARCHIVE ${ }^{2,3,4}$, \\ BARRY J COLES ${ }^{1}$, EVA SCHRECK ${ }^{2}$, LAURENCE \\ MAURICE $^{2,3}$ AND MARK REHKÄMPER ${ }^{1}$ \\ ${ }^{1}$ Imperial College London \\ ${ }^{2}$ Géosciences Environnement Toulouse \\ ${ }^{3}$ French Research Institute for Sustainable Development \\ ${ }^{4}$ ETHIQUABLE \\ Presenting Author: r.moore13@imperial.ac.uk
}

An EU regulation was introduced in 2019 that enacted stricter limits for the allowed amount of cadmium (Cd) in cacao products. The $\mathrm{Cd}$ concentration of cacao beans grown in Latin American countries, such as Ecuador, often exceed these limits. Research is therefore underway to understand the mechanisms behind the enrichment of this toxic metal and to support mitigation strategies that will help thousands of smallholders produce cacao that adheres to the new standards.

The potential of stable isotope analysis to investigate biological and environmental factors influencing the accumulation of $\mathrm{Cd}$ in cacao was first assessed by controlled hydroponic experiments ${ }^{1}$ and a pilot field study based on samples from Ecuadorian farms. ${ }^{2}$ The results suggested that (i) upregulation of heavy metal transporters in some genotypes and (ii) using cacao leaf litter as an organic fertiliser, contribute to the problematic enrichment of $\mathrm{Cd}$ in cacao.

Further samples from two commonly grown cacao varieties, soil profiles and amendments were collected from monoculture and agroforestry farms in Ecuador. This work is the first to isotopically characterise the $\mathrm{Cd}$ in whole mature cacao trees (roots, bark, branches, young, old and dead leaves, mature and green pods, mucilage and beans) and use this data to investigate $\mathrm{Cd}$ uptake, sequestration and translocation. Leaf $\mathrm{Cd}$ concentrations were found to be up to three times higher than those of roots and two to six times lower than those of bark. Relative enrichment in heavy $\mathrm{Cd}$ isotopes from roots to leaves $\left(\Delta^{114 / 110} \mathrm{Cd}_{\text {leaf-root }}=0.25 \pm 0.05,1 \mathrm{sd}\right)$, and with leaf maturity, was observed. These results corroborate previous hypotheses ${ }^{1}$ and provide new insights into $\mathrm{Cd}$ translocation mechanisms. Bean $\mathrm{Cd}$ concentrations/isotopic compositions tend to be lower/lighter, respectively, than those of leaves. The highest concentrations $(>2$ $\mathrm{mg} / \mathrm{kg}$ ) are associated with those of thick leaf litter and use of phosphate fertiliser. These findings, and others relating to the application of organic amendments such as biochar, will be discussed in the context of developing affordable, sustainable and efficient agricultural practices to reduce $\mathrm{Cd}$ phytoavailability for cacao.

${ }^{1}$ Moore et al. 2020, Horticulture Research 7(71), DOI: 10.1038/s41438-020-0292-6

${ }^{2}$ Barraza \& Moore et al. 2019, RSC Advances, 9, 3401134022, DOI: $10.1039 / \mathrm{c} 9 \mathrm{ra} 05516 \mathrm{a}$ 